\title{
Focusing on English Learners' Concerns: Investigating De-Motivational Sources of ESL Learners in Classroom Setting of a Public Sector University of Pakistan
}

\author{
Dr. Mansoor Ali ${ }^{* 1}$, Dr. Syed Shujaat Ali ${ }^{\text {*** }}$, Mr. Salman Nasir ${ }^{3 * * *}$ \\ Assistant Professor, Department of English, Kohat University of Science \& Technology, Kohat. email: sorrorali@yahoo.com \\ (Principal Author) \\ Chairman \& Assistant Professor, Department of English, Kohat University of Science \& Technology, Kohat. email: \\ s_shojaat_ali@yahoo.com (Corresponding \& Co-author) \\ Visiting Lecturer, Department of English, Kohat University of Science \& Technology, Kohat. email: salmannasir60@yahoo.com \\ (Co-author)
}

\begin{abstract}
L2 de-motivation has considerable role in diminishing or slowing down the second/L2 (English) learning outcomes. However, L2 de-motivation in general and the context of Pakistan in particular is under-researched. So, the main purpose of the study is to identify various L2 de-motivational factors of the BS Undergraduate L2 learners of the Department of English of a remote and under-researched Kohat University of Science and Technology, Khyber Pakhtunhwa, Pakistan. Drawing upon the questionnaires of the well referenced L2 de-motivation experts and also adding some items related to gender and anxiety oriented L2 demotivation, a modified closed ended questionnaire of 40 items was developed. The data was obtained from 400 (250 Male and 150 Females) L2 learners was analysed by applying the rarely used but much recommended exploratory factor analysis. Total 08 L2 de-motivational factors emerged: Teacher, syllabus, non communicative methods, L2 anxiety, lack of classroom resources, unfavourable classroom environment and rarely noted gender related L2 de-motivational factors. Moreover, in this study in contrast to earlier studies in Pakistan, we are able to not only identify the various L2 de-motivational factors in well defined forms but also construct and validate the modified questionnaire with the help of applying factor analysis. Thus the questionnaire can be exploited for future research in field of L2 de-motivation in general and particularly in Pakistan. Similarly, unlike the earlier studies, learners' negative attitudes towards English and learning its culture did not emerge as a L2 de-motivational factor. Moreover, new but equally contesting gender related L2 de-motivational factor also emerged. This study highlights that L2 teachers should adopt motivating teaching methods, interesting teaching materials and develop interesting syllabus. Moreover, L2 learners' needs analysis be given more importance for addressing their L2 de-motivation and thus enhancing their language proficiency in the Higher Education in Pakistan.
\end{abstract}

Article Received: 18 October 2020, Revised: 3 November 2020, Accepted: 24 December 2020

\section{Introduction}

There is an agreement among scholars (e.g. Chambers, 1993, Dornyei, 1998, Sakai and Kikuchi, 2009) that Second/L2 (English here) demotivation is a significant barrier in the successful L2 language learning processes and outcomes. Therefore, numerous experts explored L2 de-motivation in various contexts such as Oxford (1998, 2001) in the USA, Dornyei (1998) in Hungary, Li (2013) in China and Falout et al. (2009) and Sakai (2015) in Japan. However, L2 de-motivation unlike $\mathrm{L} 2$ motivation is underresearched (Dornyei, 2005, Krishnan and Pathan, 2013). Interestingly, L2 de-motivation like L2 motivation has been identified as a complex construct, thus emphasises to dig out the numerous aspects of L2 de-motivation. Additionally, this can be the possible reason that there exists disharmony on L2 de-motivation conceptualisation. Once conceptualised by Dornyei (2001:143) as "specific external forces that reduce or diminish the motivational basis of a behavioural intention or an ongoing action" has now integrated L2 learners' internal demotivational factors such as L2 learners' low esteem and anxiety as highlighted by many recent studies such as Sakai (2015).

Furthermore, various L2 de-motivational factors 
themselves such as teacher are conceptualised differently in various contexts by L2 learners. This suggests that L2 de-motivation has not only many but also loosely connected variables, relying on various influences like L2 learners, their sociocultural orientations and institutional setting. Moreover, most L2 de-motivation studies such as Ushioda (1998), Oxford (1998), Dornyei (1998), Arai (2006b) and Ali and Pathan (2017) confined to the cities and also targeted mostly L2 school and college levels L2 learners' de-motivational factors. Similarly, most of the studies in the field of L2 de-motivation opted for simple frequencies and means instead of much relevant statistical analytical tool of factor analysis for researching complex L2 de-motivation construct.

Keeping in view such background, this study shall research the L2 BS undergraduate learners of the Department of English of Kohat University of Science and Technology. This university though is science and arts oriented university, yet located in under-developed Khyber Pakthunkhwa province of Pakistan. While on other side, very few studies adopting simple descriptive statistical analysis such as Pathan et al. (2020) and Ali and Pathan, (2017) and Krishnan and Pathan, (2013) also conducted in other provinces of Pakistan. What makes our study interesting is the application of much recommended factor analysis (Dornyei, 2007) for digging out the underlying many but loosely connected L2 de-motivational variables. With application of factor analysis, thus, such L2 de-motivational factors are identified in precise shapes which are easy to comprehend and also investigate in future in general and especially in the under researched context of Pakistan (Robson, 2002, 2011 , Dornyei, 2007 and Field, 2013).

The context of Pakistan in interesting in English learning and teaching. On one side, learners are extremely motivated towards learning English (Shahbaz and Liu, 2012, Islam et al, 2013 and Ali et al, 2015). One other side, the learners' English proficiency is extremely low which may be due to the reason that they may be facing problems which may be contribute towards their L2 demotivation (Warsi, 2004, Samad, 2015).
Moreover, being an Islamic country, gender have no frequent interactions and are supposed to follow the Islamic and local traditions. We believe that the knowledge produced from this study can be helpful in formulating well informed L2 language planning/policies, devising effective teaching practices and materials and also considering learner's concerns important in English Language Education in Pakistan. The following sections shall first critically explore the key studies, then research question and applying the factor analysis.

\section{Literature Review}

L2 de-motivation has been the focus on attention in the L2 learning recently in comparison to L2 motivation (Sakai, 2015). Early empirical studies conducted in the 1990s in the contexts of the USA, and Europe laid the foundations of investigating L2 de-motivation. For example, Chambers (1993, 1999) using the open ended questionnaire focused on sharing their L2 learning experiences for collecting data from 191 British thirteen years old students learning German, concluded various L2 de-motivational factors. Among those were such as the teachers' discouraging behaviours like criticising learners, and teachers' centred methods of teaching, large classroom and low self esteem. However, Chambers (1993) targeted German as L2 and learning English as a L2 may have interesting L2 de-motivational factors due to its historical role and also its global status.

Similarly, Oxford (1998) targeting 250 American learners of high schools and universities distinguished through the content analysis four L2 de-motivational factors from the participants' comments on a various issues such as "talk about a classroom in which you felt uncomfortable". These L2 de-motivational factors were linked with the teacher's personal relationship with the students, including lack of caring and favouritism, the teacher's attitude towards the course or the material, style conflicts between teachers and learners and the nature of the classroom activities. However, Oxford (1998) study was limited in the 
sense that the L2 learners prompts were obtained on L2 teachers only.

Filling this gap, Ushioda (1998) collecting data through interview with open prompts from 20 Irish learners of French at the university level in the UK, found that the learners were de-motivated due to numerous reasons. Among them were due to particular teaching methods, learning tasks and course book pressure. In the context of Hungary, Dornyei (1998:20) in contrast to Oxford (1998) and Ushioda (1998) studies, targeted the fifty identified de-motivated secondary school learners of German and English languages and distinguished the following well known nine L2 de-motivational factors through the analysis of the structured interview;

a. The teacher (personality, commitment, competence, and teaching methods);

b. Inadequate school facilities (the group is so big or not at the right level, or frequent changes of teachers);

c. Reduced self-confidence (experiences of failure or a lack of success);

d. Negative attitudes towards English;

e. Compulsory nature of English study;

$f$. Interference of another foreign language being studied;

g. Negative attitudes towards the English community;

h. Attitudes among group members; and

i. Course book.

These some early studies especially Dornyei (1998) have pointed various L2 de-motivational factors which were further inspired studies notably in the other non native EFL Asian and Middle Eastern contexts like Japan, Korea and Iran (e.g. Arai, 2004, Kim et al (2018) and Afrough et al. (2014) respectively. The concept of L2 de-motivation is an external impending affluences only as per Dornyei (1998) such as teachers, courses and lack of facilities in academic and classroom setting has emerged in the early studies. Additionally, school and college levels L2 learners were mainly targeted in the early studies. It will be interesting to investigate the undergraduate universities L2 learners as due to their more exposure, and age may throw significant light on L2 de-motivation as targeted in the current study. The qualitative research techniques were adopted in the early studies which we believe need to be complemented with the sophisticated quantitative research like factor analysis due to the perhaps complex and underexplored nature of L2 de-motivation (Kim and Kim, 2015 and Dornyei, 2001). Moreover, the use of qualitative tool such as taking interview from the L2 learners on investigating sensitive issue of L2 de-motivation in the teacher centred L2 learning and teachers ideologies contexts like Asia including Pakistan may generate the valid data.

Expanding the scope of L2 de-motivation, it was investigated in the Asian contexts especially in Japan and China learning English as a foreign language in the beginning of the new millennium. In the context of Japan, Arai (2004) categorised 33 university L2 learners' comments into four L2 de-motivational factors from the open ended questionnaire which was focused on the learners' reflections of the past experience of learning L2. These are; teachers, classes, class atmosphere and others. In line with the previous studies such as Dornyei (1998), teachers accounted for $46.7 \%$ of the total comments which highlight that teacher was considered as the main source of L2 demotivation. This becomes more crucial in case of the Asian contexts as teachers is believed to be source of authority in teaching L2 as lamented by Islam (2013) and Mansoor (2005) in Pakistan and Sakai and Kakuchi (2009) in Japan. Haswega (2004) in contrast to Arai (2004) interviewed 125 junior and 98 high school L2 learners on the basis of a questionnaire with open ended questions. She like Arai (2004) and early 1990s studies, found teachers as the major source of the learners' L2 de-motivation.

In contrast to Arai (2004) and Haswega (2004) studies, Falout and Maruyama (2004:07) developed 49 closed items questionnaire mainly on the basis of Dornyei's (1998) nine categories and collected data from 164 university L2 learners. They found main source of their L2 demotivation were self confidence, negative 
attitudes towards L2, teachers and negative attitudes of their group members. Tsuchiya (2004a, 2004b) targeting 204 college L2 learners and adopting factor analysis on 26 items questionnaire unlike earlier studies in Japan, identified six L2 de-motivational factors. These are (a) sense of English uselessness, (b) sense of incompetence, (c) little admiration, (d) inconsistent way of studying, (e) sense of discouragement, and (f) lack of acceptance as reported by Kikuchi and Sakai (2009:187). Tsuchiya's (2004a, 2004b) findings could be considered more significant as factor analysis as per Dornyei (2007) can be exploited for further investigation on L2 de-motivation not only in the Japan but also other contexts in the world. Drawing upon Tsuchiya's (2004a, 2004b) and Dornyei's (1998) and Falout and Maruyama (2004) findings, Tsuchiya (2006a, 2006b) distinguished nine L2 de-motivational factor among Japanese L2 learners. There are "teachers, classes, compulsory nature of English study, negative attitude toward the English-speaking community, negative attitude toward English itself, lack of self-confidence, negative group attitude, lack of a positive English speaking model, and ways of learning" as cited in Kikuchi and Sakai (2009:187). It can be said the both external and internal L2 de-motivational factors were highlighted by Tsuchiya (2006a, 2006b) unlike the early 1990 studies of the West.

Combining the main findings of earlier Japan based L2 de-motivational studies such as Falout and Maruyama (2004) and Tsuchiya (2006a, 2006b), Sakai and Kikuchi (2009) developed 35 closed -items questionnaire and collected data from 112 university L2 learners. They identified five L2 de-motivational factor with the help of factor analysis. These are: "(a) course books, (b) inadequate school facilities, (c) test scores, (d) non-communicative methods, and (e) teachers' competence and teaching styles" (Sakai and Kikuchi (2009:192). Kikuchi (2015) in his recent book on "De-motivation in Second Language Acquisition: Insights from Japan" also highlighted various L2 de-motivational factors which includes both external and internal factors among Japanese L2 learners. Similarly to Sakai and Kikuchi (2009), Falout et al. (2009) applying factor analysis on 900 university L2 learners identified nine L2 de-motivational factor from 52 closed items questionnaire. Three were external L2 demotivational factors (teacher immediacy, grammar translation method, and course level), three internal L2 de-motivational factors (self denigration, values and self confidence) and three reactive motivational factors (help seeking, enjoyment seeking and avoidance) Falout et al. (2009:403).

Summarising the above Japanese based L2 demotivational studies, it can be said that unlike the earlier studies conducted in the context of USA and Europe, well developed quantitative research techniques such open and closed questionnaire and also much recommended measuring instruments of factor analysis (Field, 2005) for relatively new and complex construct like L2 demotivations was applied in few studies such as Tsuchiya (2004a, 2004b), Sakai and Kikuchi (2009) and Falout et al. (2009). Additionally, unlike the earlier studies, these studies highlighted not only the external but also the internal L2 learners' de-motivational factors and thus it can argued that the scope of L2 de-motivation was extended which highlights further investigation in other countries including Pakistan as targeted in the current study. However, most of these studies remain limited to L2 school and college level learners, thus highlighting the need to conduct more L2 de-motivation studies on L2 learners at university levels as targeted in the current study. Empirical studies on L2 learners de-motivation in China, were initiated around the end of the first decade of the new millennium ( e.g. (i.e. $\mathrm{Hu} \&$ Cai, 2010; Zhou \& Wang, 2012) as reported by Li and Zhou (2017). Following the mixed methods (first interview and then questionnaire), $\mathrm{Hu}$ and Cai (2010) from 170 non major L2 learners of English, found six L2 de-motivational factors. These were the learning interest, learning goal, valence, anxiety, attribution, learning environment as cited by Li and Zhou (2017:129) 
One of the interesting finding was unlike the earlier studies was that anxiety was emerged as L2 de-motivational factor which is relevant especially in the non native contexts as noticed by Samad (2015) in Pakistan.

Zhou and Wang (2012) found five L2 demotivational factors (both internal and external) among 766 college L2 learners in China. These are "2 internal factors (lack of intrinsic interest, lack of effective learning strategy) and 3 external factors (teachers' competence and teaching style, curriculum and learning material, defective teaching attachments)" as cited in Li and Zhou (2017: 129). Li (2013) found internal L2 demotivational factors among the college L2 learners which are; decrease in self confidence, insufficiency in affective cognition, learning strategies deficiency, and lack of intrinsic interest. One main significant finding of Li's (2013) study was that lack of intrinsic feelings can be source of L2 de-motivation which can play significant role in the successful L2 learning as argued by Noels et al. (2000).

Quite recently, targeting 367 L2 learners in the non key local universities, unlike the earlier Chinese based L2 de-motivations studies, Li and Zhou (2017) distinguished many L2 demotivational factors. These are "internal factors (lack of intrinsic interest, experience of failure and lack of confidence, and unclear study goal) and external factors (teaching material, teaching process and teaching content, significant others, teachers' teaching competence and attitude of teachers, the relationship between teachers and students, teaching facilities and teaching environment" (Li and Zhou, 2017:128). Moreover, they also noted that external can have more negative influence than their internal L2 motivational factors on their L2 motivation. Most recently, Li et al. (2020:671) with the help of factor analysis identified "teacher-related factor, non-communicative teaching mode, lack of intrinsic interest, negative peer influence, and undesirable teaching conditions" among the under-graduate L2 learners.

Analysing, Chinese based studies, it can be argued that that scope of L2 de-motivational factors was further extended as L2 de-motivational factors such as anxiety and lack of clear goals were also emerged as source of L2 de-motivations for L2 learners. However, once again, there is scarcity of applying factor analysis as main instrument for investigating L2 de-motivation in China.

Empirical studies on L2 de-motivation has also been conducted other in the EFL non native context especially in Korea and Iran. For example, Kim and Seo (2012:160) using questionnaire data from 6,301 L2 learners from schools in Korea, noted the following L2 de-motivational factors; (a) the negative impact of the English teacher such as incongruence with students' needs teachers' impatience and disinterest in teaching and in their students. (b) excessive social expectation of English proficiency and (c) the widening English proficiency gap among the students. The excessive social expectation as a cause of L2 learners' de-motivational may be crucial in the non context where people and parents expect a lot from L2 learners as reported by Ali et al. (2015) in the context of Pakistan.

Similarly, in Iran, Kaivanpanah and Ghasemi (2011) applying factor analysis concluded that L2 de-motivational sources are a) learning contents, materials, and facilities, b) attitude towards English speaking community, c) the teacher, d) experience of failure, and e) attitude towards second language learning. Recently, Aliakbari and Hemmatizad (2015:106) also adopted factor analysis, identified five L2 de-motivational factors. These are "learning contents and materials, teachers' Competence and teaching Styles, inadequate school facilities, lack of intrinsic motivation, and test scores". Irani based studies seems to be focus on mainly questionnaire and also adopting factor analysis for investigating L2 de-motivation.

In context of Pakistan, to the best of my knowledge a few studies have been conducted on L2 de-motivation. For example, Rahman et al. (2010) adopting mixed methods (interview and questionnaire) found some L2 de-motivational factors among the school learners. These are 5786 
"complicated English grammar rules, difficulty in understanding listened English, spelling and reading mistakes, difficult textbook, large memory load, low self-esteem and anxiety" (Rahman et al. (2010:210). Likewise, Khattak et al. (2011:1600) with the help of mixed methods noted that L2 learners have L2 anxiety as "that the students felt anxious of making mistakes and about teachers' correcting their mistakes in the classes; they felt nervousness about failing the exams". However, they did not investigate that L2 anxiety can be served as their L2 de-motivation. Quite recently, Ali and Pathan (2017) targeting 150 college L2 learners in the province of Baluchistan, reported various sources from the descriptive analysis of the adopted questionnaire of Kakuchi and Sikai (2009). These six various L2 de-motivational were "grammar-based teaching, teacher's behaviour, course contents and teaching materials, effects of low test score, classroom environment and lack of self-confidence and interest" (Ali and Pathan, 2017:81).

The critical summary of the above literature on L2 de-motivation highlight some important points. First, most of the studies are conducted either in the West or in the EFL contexts, thus highlighting the need of conducting more studies on the ESL contexts including Pakistan. Second, L2 demotivation is a complex constructs containing many and also loosely connected variables depending on the L2 learners, levels, contexts and linguistic and cultural orientations. Third, most of L2 de-motivation remain limited to the L2 school and college levels learners, thus it can be argued that L2 learners at university level need to be targeted. Fourth, though not only the qualitative, quantitative but also mixed methods are exploited, yet the well recommended measuring instrument such as the factor analysis (Field, 2013) is rarely applied in general and notably in the ESL context including Pakistan. Finally, L2 learners from the rural background are ignored as majority of the studies on L2 de-motivation remain limited to the L2 urban or cities learners. Keeping in view the critical review of L2 de-motivation, our research question is as follows;
What are the L2 de-motivational factors of Pakistani undergraduate learning English as a second language?

\section{Research Design}

Exploratory factor analytical technique was applied on the survey based questionnaire related to the L2 learners' de-motivational factor at the university level.

\subsection{Context and Participants}

A sample of 400 under-graduate BS L2 learners were the participants from a relatively new science and arts oriented university from the under-developed province of Kyhber Pakhtunkhwa, located in the North part of Pakistan. The participants are studying English language and Literature as the main subject and most of them belong to the villages. Such sample is considered to be suitable for conducting applying factor (Dornyei, 2007 and Field, 2013).

\subsection{Procedures for Applying Factor Analysis}

The reliability of the questionnaire items was checked through Cronbach Alpha (.79) which was satisfactory as per Dornyei (2007) and Pallant (2007). Then. four main procedures as recommended by Dornyei (2007), Field (2013) and Tabachnick and Fidell (2013) were followed. First, the factorilabity of the items was checked through KMO (Kaisor-Mayor-Olkin) of sample adequacy (.86) and Bartlett Test of Sphericity (.000) were applied which were good (Dornyei, 2007). Second, eigenvalues were fixed greater than 1. However, Scree Plot with clear cut like human elbow was applied in order to compensate the deficiency of the fixed eigenvalues as per Dornyei's (2007) recommendations. Third, Varimax was exploited in the rotation for receiving the emerged factor in more well defined order. Last, the factor loading value was fixed greater than .30 for more robust factors (Sakai and Kikuchi, 2009).

However, couples of items (17, 40, 23, 32 ) related to the L2 learners' negative attitudes towards English as a source of L2 de-motivation were noted as confusing. Moreover, items $(23,28)$ 
related to gender as a source of L2 de-motivation was also found confusing. Consequently, after applying factor analysis a number of times, total 08 emerged L2 de-motivational factors were retained as in the following table 1 as we believe these are the most meaningful to be interpreted. The retained 08 factors explained 0.60 variance of the solution.

Table:01 Output of Factor Analysis of L2 De-motivational Factors

Items: I feel de-motivated due to............... Loaded Values

\section{Factor 1}

34. Teacher's lack of competency in English.

05 . Teacher's boring teaching method.

15. Teacher's making fun of students mistakes.

21. Teacher's poor communicative ability in English.

25. No encouragement from teacher.

11. Teacher's bad attitudes towards students.

27. Teacher is not allowing to ask question in class.

18. Teacher is not easily accessible.

29. Not showing respect to students by the teachers.

\section{Factor 2}

37. Too long text books.

02. Boring lessons.

30. Focus on providing grammar knowledge only.

24. Boring and difficult exercises.

16. Teacher's focus on teaching books only.

08. Teachers' not using speaking practices of textbooks.

\section{Factor 3}

06. Focus on teaching how to read and write only.

20. Lack of chances of speaking English in classroom.

09. Noting the lecture points all the time.

01 . Teacher's explanation of grammar rules all time.

\section{Factor 4}

36. Feeling of being anxious in class.

07. Being scared of speaking English.

13. worry about responding in English.

19. Laughing of teacher and students on my wrong pronunciation.

\section{Factor 5}

35. No use of Audio-Visual Aids in classroom.

10. No use of Multimedia for learning and using English.

12. No proper chairs and computers.

\section{Factor 6}

14. Not scoring the desired grades in English.

04. Strict marking in English by the teachers.

26. Discrimination in grading by the teachers.

Factor 7

39. No or little cooperation from the classmates. 
03. large classes.

31. No speaking opportunities in class.

Factor 8

22. Gender issues in classroom.

38. Gender is the problem in speaking English.

33. Male or Female feel shy while speaking in English.

28. Laughing of opposite gender on my English.

\subsection{Labelling of the Emerged L2 De- Motivation Factors}

\section{Factor 1: Teacher Related L2 De-motivation}

Table 01 indicates that total 08 factor are identified. Factor 01 obtained loading from items $(34,05,15,21,25,11,27,18,29)$. All these items are exclusively focused on teachers' rude behaviour, lack of competency and strict evaluation. Therefore, the factor 01 is labelled as "Teacher Related L2 De-motivation" as identified by Gorham and Christophel (1992), Sakai and Kikuchi (2009), Lamb (2017), Ali and Pathan (2017) Renandya (2015).

\section{Factor 2: Syllabus Related L2 De-motivation}

Factor 2 received items from $(37,02,30,24,16$, 08). All these items reflects syllabus related issues and therefore, labelled as "Syllabus Related L2 De-motivation". This L2 de-motivation is also noted by Dornyei (1998), Pathan et al. (2020), Afrough et al. (2009) and Meshkat and Hassani (2012).

\section{Factor 3: Non Communicative Method Related}

\section{L2 De-motivation}

Factor 03 is loaded with items $(06,20,09,01)$. All these items basically rooted in grammar based teaching methods and syllabi which gives L2 learners less opportunities of using English in communicative situation. So, the factor 3 is labelled as "Non Communicative Method Related L2 De-motivation" which is identified in Khattak et al. (2011), Li et al. (2020), Afrough et al. (2014), Falout et al. (2009) and Song and Kim (2017).

\section{Factor 4: L2 Anxiety Related De-motivation}

Factor 4 received loading from the items (36, 07, 13, 19). All these items are focused on the L2 learners' anxious feelings about learning and using
English. So, the factor 4 is labelled as" L2 Anxiety Related De-motivation" which is also echoed in $\mathrm{Hu}$ and Cai (2010), $\mathrm{Hu}$ (2011) and Khattak et al. (2011). However, L2 anxiety as a source of L2 de-motivation is rarely noted in the field of L2 de-motivation which also highlight the need to further investigate it.

\section{Factor 5: Classroom Resources L2 Related De- motivation}

Items $(35,10,12)$ are loaded on factor 5 . These items represent clearly that lack of resources slow down their L2 motivation. Therefore, this factor is labelled as "Classroom Resources L2 Related Demotivation" as noted by

Kikuchi (2006), Zhang (2007), and Chili et al. (2020).

\section{Factor 6: Grades Related De-motivation}

Factor 6 obtained loading from items $(14,04,26)$ which represent that L2 learners are worried about not obtaining good grades. So, the factor 6 is labelled as "Grades Related De-motivation" as noted by Ali and Pathan (2017), Little (2008) and Sakai and Kikuchi (2009).

\section{Factor 7: Unfavorable Classroom Environment Related L2 De-motivation}

The items $(39,03,31)$ loaded on factor 7 represent the unfavourable situation in classroom. Therefore, the factor 7 is labelled as "Unfavorable Classroom Environment Related L2 Demotivation" as identified by Afrough et al. (2014) and Ali and Pathan (2017).

\section{Factor 8: Gender Related L2 De-motivation}

Though two items $(22,38)$ are loaded on factor 8 , yet these are very important as these points towards the gender related issues while learning 
and using L2 in classroom. These items reflect that L2 learner are feeling demotivated due to gender related issues like speaking with each other. One reason can be as highlighted by Ali et al. (2015) that the context of Pakistan in general and notably Khyber Pakhtunkhwa is conservative in the socio-cultural ideologies. To the best of our knowledge, such L2 de-motivational factor is rarely identified in the field of L2 de-motivation. Therefore, it needs to be further investigated.

\section{Discussion}

Applying the exploratory factor analysis, total nine L2 de-motivational factors emerged. The identified L2 de-motivational also emerged in other native such as Chambers (1999) and Oxford (1998) and non native such as Dornyei (1998), Sakai and Kakuchi (2009) and Kim (2015) contexts. However, gender related L2 demotivational factor is rarely noted in L2 demotivation. The gender related L2 de-motivational factor also highlights the need to be investigated further, especially in the conservative countries and also more qualitative approach may be followed for digging out more aspects of gender related L2 de-motivational factor.

Another interesting aspect of the study is that unlike other studies such as Dornyei (1998), Tyguchi (2004a, 2006b), Keblawi (2005), Sakai and Kakuchi (2009) negative attitudes towards English, its learning and culture did not emerge as L2 de-motivational factor. This may be due the reason that English is not only the dominant language but also becoming local languagePakistani English as highlighted by Mahboob (2009) and Islam et al. (2013). Moreover, L2 learners in Pakistani universities want to learn and use English as an international language as concluded by Ali et al. (2015).

This study like Falout et al.(2014) and Sakai (2009, 2015) highlighted that L2 de-motivation is a complex construct and composed of many and interrelated components. Such conceptualisation of L2 de-motivation can also guide about adopting the relevant research design such as mixed methods for digging out the underlying many scattered de-motivational factors and the impact of these motivational factors on the learners' language proficiency.

This study also emphasised that conceptualisation and also investigation of L2 de-motivation should not be restricted to the external impeding factors such as teacher and classroom environment as highlighted by earlier studies of Chambers (1999) and Oxford (1998). Internal L2 de-motivational factors such as learners' L2 anxiety as noted by in the may be included in the conceptualisation and investigating of L2 de-motivation. In contrast to studies such as Kikuchi and Sakai (2009), Kim (2016) learner's related L2 de-motivational factors emerged less as compared to the external related L2 de-motivational factors. The possible reason can be that the L2 learners have much exposure to the use and learning of L2 and probably feel confident enough to learn L2. However, this needs to be further investigated.

However, further the identified L2 demotivational may be further investigated with reference to measuring the impact of these L2 demotivational factors on the learners' proficiency which this study could not investigate. Moreover, how the learners, especially teachers cope with these identified L2 motivational factors also need to be investigated so that L2 learning can be successful (Wyatt, 2013).

\section{Conclusion}

The main purpose of the study was to identify the BS Undergraduate English learners' L2 demotivational factors. For this purpose, the factor analysis was performed on the closed questionnaire and identified total 08 demotivational factors among the learners. This study in contrast to other studies in Pakistan applied the relevant and also sophisticated statistical tool of factor for measuring the multi but loosely connected L2 de-motivational variables among the learners. However, the impact of these identified L2 de-motivational needs to be explored on the learners' language proficiency and also may be extended to other provinces in Pakistan and across the world in the 
field of L2 de-motivation.

\section{References}

[1] Afrough, T., Rahimi, A.,\& Zarafshan, M. (2014).Foreign Language Learning De-motivation: A Construct Validation Study. Social and Behavioral Sciences, 136, 49-53.

[2] Ali, M., Wyatt, M., and Laar, D. V. 2015. Pakistani postgraduate students' orientations for learning English as a second language: A factor analytic study. System 51(1): 77-87.

[3] Ali, M., \& Pathan, Z. (2017). Exploring factors causing de-motivation and motivation in learning English language among college students of Quetta, Pakistan. International Journal of English Linguistics 7 (2), 81-90.

[4] Aliakbari, M and Hemmatizad, M, (2015) On Students' De-Motivation, Gender, Major, and Educational Level in Iranian EFL Context, English Language Teaching; 8(4).

[5] Arai, K. (2004). What demotivates language learners?: Qualitative study on de-motivational factors and learners ${ }^{6}$ reactions. Bulletin of Toyo Gakuen University, 12(3), 39-47.

[6] Chambers, G. N. (1993). Talking the 'de' out of de-motivation. Language Learning Journal, 7: 13-16.

[7] Chambers, G. (1999). Motivating Language Learners. Multilingual Matters, Clevedon.

[8] Dörnyei, Z. (1998). De-motivation in foreign language learning. Paper presented in the TESOL '98 Congress, Seattle, WA, March.

[9] Dörnyei, Z. (2001). Teaching and researching motivation. Harlow: Longman.

[10] Dörnyei, Z. (2005). The psychology of the language learner: Individual differences in second language acquisition. Mahwah, NJ: Erlbaum.
[11] Dörnyei, Z. (2007). Research Methods in Applied Linguistics: Quantitative, Qualitative and mixed Methodologies. Oxford: Oxford University Press.

[12] Dörnyei, Z., \& Ushioda, E. (2011). Teaching and researching motivation (2nd ed.). Harlow: Longman.

[13] Falout, J., \& Maruyama, M. (2004). A comparative study of proficiency and learner demotivation. The Language Teacher, 28, 3-9.

[14] Falout, J., Elwood, J., \& Hood, M. (2009). Demotivation: Affective states and learning outcomes. System, 37(3), 403417.

[15] Field, A. P. (2005). Discovering statistics using SPSS: (and sex, drugs and rock ' $n$ ' roll) (2nd ed.). London: Sage Publications.

[16] Field, A. P. (2013). Discovering statistics using IBM SPSS Statistics (4th ed.). London: Sage Publications.

[17] Gorham, J., \& Christophel, D. M. (1992). Students' perceptions of teacher behaviors as motivating and de-motivating factors in college classes. Communication Quarterly, 40(3), 239-252.

[18] Hasegawa, A. (2004). Student demotivation in the foreign language classroom. Takushoku Language Studies, 107, 119-136.

[19] Hu, W., \& Cai, J. (2010). Construction of Model of De-motivation in English Learning. Foreign Language Education, 31(3), 41-49.

[20] Hu, R. (2011). The relationship between de-motivation and EFL learners' English language proficiency. English Language Teaching, 4(4), 88-96.

[21] Islam, M., Lamb, M., and Chambers, G. (2013). The L2 Motivational Self System and National Interest: A Pakistani Perspective. System 41(2):231-244.

[22] Islam, M. (2013). L2 motivational selfsystem and relational factors affecting the L2 motivation of Pakistani students in the public universities of Central Punjab, 
Pakistan. Unpublished $\mathrm{PhD}$ dissertation. University of Leeds, Leeds. Retrieved from http://etheses.whiterose.ac.uk/5054/.

[23] Lamb, M. (2017). The motivational dimension of language teaching. Language Teaching, 50(3), 301-346.

[24] Li, C., \& Zhou, T. (2017). A questionnaire-based study on Chinese university students' de-motivation to learn English. English Language Teaching, 10(3).

[25] Li, C. L., Dou, R., \& Zhang, S. (2020). A Correlational Study on Psychological Resilience and L2 De-motivation among Chinese EFL Learners. Revista Argentina de Clínica Psicológica, (3):670-681.

[26] Keblawi, F. (2005). De-motivation among Arab learners of English as a foreign language. Proceedings of the Second International Online Conference on Second and Foreign Language Teaching and Research, 49-78.

[27] Kaivanpanah, S. H., \& Ghasemi, Z. (2011). An investigation into sources of demotivation in second language learning. Iranian Journal of Applied Linguistics, 5(3), 89-110.

[28] Khattak, Z. I., Jamshed, T., Ahmad, A., \& Baig, M. N. (2011). An Investigation into the Causes of English Language Learning Anxiety in Students at AWKUM. Procedia - Social and Behavioral Sciences, 15, 1600-1604.

[29] Kikuchi, K. (2006). Revisiting English entrance examinations at Japanese universities after a decade. JALT Journal, 28(1), 77-96.

[30] Kikuchi, K. \& Sakai, H. (2009). Japanese learners' de-motivation to study English: A Survey Study. JALT Journal, 31(2), 183204.

[31] Kikuchi, K. (2009). Listening to our learners' voices: What demotivates Japanese high school students? Language Teaching Research, 13(4): 453-471.

[32] Kikuchi, K. (2015). De-motivation in second language acquisition: Insights from Japan. Bristol, UK: Multilingual Matters.

[33] Kikuchi, K. (2017). Re-examining demotivators and motivators: A longitudinal study of Japanese freshmen's dynamic system in an EFL context. Innovation in Language Learning and Teaching, 11(2), 128-145.

[34] Kim. T.-Y., \& Seo, H.-S. (2012). Elementary school students' foreign language learning de-motivation: A mixed methods study of Korean EFL students. The Asia-Pacific Education Researcher, 21(1), 160- 171.

[35] Kim, S. (2015). De-motivation and L2 motivational self of Korean college students. English Teaching, 70(1), 29-55.

[36] Kim, T.Y., \& Kim, Y.K. (2015). Elderly Korean learners' participation in English learning through lifelong education: Focusing on motivation and de-motivation. Educational Gerontology, 41(2), 120-135.

[37] Kim, T.Y., Kim, Y., \& Kim, J.Y. (2018). A qualitative inquiry on EFL learning demotivation and resilience: A study of primary and secondary EFL students in South Korea. Asia Pacific Education Researcher (Springer Science \& Business Media B.V.), 27(1), 55-64.

[38] Krishnan, K. S. D., \& Pathan, Z. H. (2013). Investigating De-motivation in Learning English: An Extension to Sakai and Kikuchi's (2009) Framework. Advances in Language and Literary Studies, 4(2), 124-131.

[39] Little John, A. (2008). The tip of the iceberg: Factors affecting learner motivation. RELC Journal, 39(2), 214225.

[40] Mansoor, S. (2005). Language planning in higher education. A case study of Pakistan. Karachi: Oxford University Press.

[41] Mahboob, A. (2009). English as an Islamic language: A case study of Pakistani 
English. World Englishes, 28(1), 175-189.

[42] Meshkat, M., \& Hassani, M. (2012). Demotivating factors in learning English: the case of Iran. Procedia-Social and Behavioral Sciences, 31, 745-749.

[43] Noels, K. A., Clément, R., \& Pelletier, L. G. (2000). Intrinsic, Extrinsic, and Integrative Orientations of French Canadian Learners of English. Canadian Modern Language Review, 57(3), 424-42.

[44] Oxford, R. L. (1998). The unravelling tapestry: Teacher and course characteristics associated with demotivation in the language classroom. Paper presented at TESOL 98 Conference, Seattle, WA.

[45] Oxford, R. L. (2001). The bleached bones of a story': Learners' constructions of language teachers. In M. Breen (Ed.), Learner contributions to language learning: New directions in research (pp. 86-111). London: Longman.

[46] Pallant, J. (2007). SPSS survival manual: A step by step guide to data analysis using SPSS (4th ed.). Maidenhead: Open University Press.

[47] Pathan, Z.H., Ismail, S.A. M .M. and Fatima, I. (2020). English language learning de-motivation among Pakistani university students: do resilience and personality matter?", Journal of Applied Research in Higher Education

[48] Rahman, F. C, N. B. Jumani, and A. Basit,(2010). Motivating and demotivating factors among learners. International Journal of Academic Research, 2(1), 206212.

[49] Renandya, W. A. (2015). L2 motivation: Whose responsibility is it? English Language Teaching, 27(4), 177-189.

[50] Robson, C. (2002). Real world research: A resource for social scientists and practitionerresearchers (2nd ed.). Oxford: Blackwell.

[51] Robson, C. (2011). Real world research: A resource for social scientists and practitionerresearchers (3rd ed.).

Chichester: Wiley.

[52] Sakai, H., \& Kikuchi, K. (2009). An analysis of demotivators in the EFL classroom. System, 37(1), 57-69

[53] Samad, A. (2015). An Exploratory Investigation of Foreign Language Classroom Speaking Anxiety Amongst Pakistani EFL University Students (Unpublished $\mathrm{PhD}$ thesis). University of Exeter, Exeter, UK.

[54] Shahbaz, M., \& Liu, Y. (2012). Complexity of 12 motivation in an Asian ESL setting. Porta Linguarum, 18, 115131.

[55] Song, B., \& Kim, T. Y. (2017). The dynamics of de-motivation and remotivation among Korean high school EFL students. System, 65, 90-103.

[56] Tabachnick, B. G., \& Fidell, L. S. (2013). Using multivariate statistics (6th ed.). London: Pearson.

[57] Tsuchiya, M. (2004a). Nihonjin daigakuseino eigogakushuuheno demotivation (Japanese university students ${ }^{6}$ de-motivation to study English). The Chugoku Academic Society of English Language Education Kenkyukiyo, 34, 5766.

[58] Tsuchiya, M. (2004b). Factors in demotivation concerning learning English: A preliminary study of Japanese university students. The Kyushu Academic Society of English Language Education (KASELE), 32, 39-46.

[59] Tsuchiya, M. (2006a). Factors in demotivation of lower proficiency English learners at college. The Kyushu Academic Society of English Language Education (KASELE), 34, 87-96.

[60] Tsuchiya, M. (2006b). Profiling of lower achievement English learners at college in terms of demotivating factors. Annual Review of English Language Education in Japan (ARELE),17, 171-180.

[61] Ushioda, E. (1998). Effective motivational 
thinking: A cognitive theoretical approach to the study of language learning motivation. In E. A. Soler \& V. C. Espurz (Eds.), Current issues in English language methodology (pp. 77-89). Castelló de la Plana, Spain: Universitat Jaume I.

[62] Warsi, J. (2004). Conditions under which English is taught in Pakistan: An applied linguistic perspective. Sarid Journal. 1(1), $1-9$.

[63] Wyatt, M. (2013). Motivating teachers in the developing world: Insights from research with English language teachers in Oman. International Review of Education, 59(2), 217-242.

[64] Zhang, Q. (2007). Teacher misbehaviors as learning de-motivators in college classrooms: A cross-cultural investigation in China, Germany, Japan, and the United States. Communication Education, 56(2), 209-227.

[65] Zhou, C., \& Wang, W. (2012). Demotivators Analysis of Chinese University EFL Learners. Foreign Languages in China, 9(1), 48-55. 